\title{
De specialist van morgen; een betere opleiding
}

\author{
O.P. Bleker
}

\section{Samenvatting}

De medisch specialist van morgen werkt in een team, een maatschap van specialisten. Hij werkt nauw samen met andere zorgverleners, hij beheerst de basis van het specialisme en heeft een persoonlijk aandachtsgebied. Om assistenten voor te bereiden op dit nieuwe functieprofiel worden de algemene eindtermen belangrijker in de opleiding. Het gaat daarbij om competenties op het gebied van de medische zorg, maar ook om communicatie, samenwerking, management, levenslang leren en maatschappelijke moed en verantwoordelijkheid.

Deze veranderingen worden mogelijk door opleiders bij te scholen op het gebied van opleiden en beoordelen.

\section{Inleiding}

In de opleiding tot medisch specialist moet goed worden nagedacht over het profiel van de patiënt, de dokter en de zorgverlening van de toekomst. Deze belangrijke actoren in de gezondheidszorg veranderen snel en nieuwe zorgverleners moeten zodanig worden toegerust dat zij met deze veranderingen kunnen omgaan. Het klassieke model waarin 'tijdens de opleiding voldoende werd geleerd om de toekomst aan te kunnen' moet transformeren naar een model dat assistenten 'tijdens de opleiding zodanig laat leren dat zij voortdurend in staat zijn en blijven om nieuwe kennis en vaardigheden kritisch te beoordelen en te verwerven'. Belangrijk is daarbij niet zozeer het bijbrengen van de kennis en de vaardigheden van nu, maar veeleer het aanleren van een attitude die levenslang in staat stelt tot veranderen en vernieuwen. Het Centraal College Medische Specialismen (CCMS) heeft daarom het initiatief genomen om samen met de wetenschappelijke verenigingen te werken aan de nieuwe opleiding van morgen.

\section{De patiënt van de toekomst}

De patiënt van de toekomst zal in het algemeen beter geïnformeerd zijn dan de patiënt van vroeger en nu. Het is een interessante ontwikkeling dat juist op het gebied van de gezondheidszorg een belangrijk gedeelte van het kennisdomein ook bekend raakt bij het publiek. Er bestaat grote interesse van de kant van het publiek voor gezondheidszaken en de media doen hun best in die behoefte te voorzien. In de Verenigde Staten en in het Verenigd Koninkrijk, waar processen zoals onderzoek en verbetering van de kwaliteit van de gezondheidszorg (quality assessment \& improvement en ook risk management) verder zijn ontwikkeld dan in ons land 1, is die publieke belangstelling nog veel groter.

De patiënt van de toekomst wil goed geïnformeerd zijn over de voor- en nadelen van de verschillende behandelingsmogelijkheden en meer weten van de kennis en vaardigheden van het betrokken behandelingsteam. We moeten dus in de toekomst meer meten en weten wat wij doen. Dit zijn wij vanzelfsprekend ver- 
plicht aan onszelf als beroepsgroep, maar ook aan de patiënt, de verzekeraars en de overheid. Juist deze processen stellen ons in staat ons handelen te analyseren, bij te sturen en te verbeteren. Het zal duidelijk zijn dat volstrekte openheid van zaken binnen de beroepsgroep, maar zeer uitdrukkelijk ook er buiten, vanzelfsprekend moet zijn. Alles komt ooit aan het licht. Het is daarom bij gerezen problemen verstandig ook het minder goede nieuws zelf publiek te maken en niet af te wachten totdat het ooit (en altijd) uitlekt.

De patiënt van de toekomst is niet anders dan de patiënt van nu inzake de verwachting voldoende tijd en aandacht, respect en empathie van het zorgteam te krijgen. Het is interessant waar te nemen dat deze klassieke begrippen, die de relatie tussen patiënt en dokter bepalen, ook in deze tijd van snelle technische vooruitgang van groot belang zijn en blijven. Een belangrijk verschil is wel dat de mondige patiënt van morgen ons nalatig handelen of falen niet meer stilzwijgend zal laten passeren, maar dat hij zal klagen. Het begrip 'patient centered care' is dus geen loos begrip, maar iets dat voortdurende aandacht verdient tijdens de opleiding tot basisarts en de vervolgopleiding tot medisch specialist. ${ }^{2}$

\section{De dokter van de toekomst}

Het arbeidstijdenbesluit voor assistenten in opleiding en andere maatschappelijke processen hebben het individuele leven van de betrokkenen ingrijpend veranderd en zonder twijfel verbeterd. Hierdoor is een nieuwe balans ontstaan tussen werk en thuis. Dat betekent niet dat de huidige assistenten in opleiding het vak minder belangrijk vinden dan vroeger. Het betekent wel dat ook andere zaken van het leven, zoals de partner, de kinderen en thuis relatief meer aandacht vragen en ook krijgen dan vroeger. Zeer waarschijnlijk zal deze verandering, die zich nu binnen de opleidingen heeft voltrokken, ook directe consequenties hebben voor de praktijk van de gezondheidszorg van de toekomst. De dokter van de toekomst is veel vaker een vrouw (van de studenten is nu 70\% en van de agio's 56\% een vrouw), heeft vaker een partner, wordt vaker zwanger tijdens de opleiding, heeft kinderen en wil ouderschapsverlof (ook de partner). ${ }^{3}$ De dokter van de toekomst zoekt een nieuwe balans tussen werk en thuis, wil minder dienst doen dan nu gebruikelijk is, wil vaker parttime werken (ook de mannen) en zou wel eens veel eerder kunnen stoppen met de uitoefening van zijn beroep dan nu voor mogelijk wordt gehouden.

$\mathrm{Al}$ deze ontwikkelingen maken wel dat de specialist niet meer zoals vroeger tot zijn vijf en zestigste jaar en full-time zal werken. Dit betekent dat ons opleiden in relatie tot de benodigde specialistische menskracht minder effectief is geworden. Het staat nog te bezien of bij de huidige toekomstverwachtingen ten aanzien van de menskracht met deze ontwikkelingen, die wel eens progressief zouden kunnen zijn, voldoende is rekening gehouden.

De dokter van de toekomst heeft een betere vooropleiding gehad en leert sneller zelfstandiger dan vroeger. De dokter van de toekomst kan goed en snel omgaan met computers en kent de fascinerende mogelijkheden van de bronnen op het internet zoals Pubmed, de Cochrane Library en de richtlijnen van nationale en internationale wetenschappelijke verenigingen. Dat maakt de medisch student en ook de assistent in opleiding in de toekomst zeer geschikt voor actieve participatie in het proces ter verbetering van de opleiding en de praktijk van het vak. 


\section{De zorg in de toekomst}

De medisch specialistische zorg zal in de toekomst worden geboden door grote maatschappen in grote ziekenhuizen. Er zijn wel politieke geluiden over de charme en het belang van kleine ziekenhuizen, maar daarbij wordt geen rekening gehouden met het menskrachtprobleem, in het bijzonder bij de werkzaamheden buiten kantooruren. Alle maten van een specialistengroep beheersen de basis van het specialisme en kunnen zelfstandig de gewone en veel voorkomende tweedelijns problematiek van het specialisme aan. Daarnaast hebben zij allemaal een eigen aandachtsgebied en zullen niet alle aspecten van het specialisme meer overal worden verzorgd. Er zal daarom meer dan nu het geval is worden samengewerkt door teams van specialisten of zelfs door hele ziekenhuizen. Op grond van volume, kwaliteit, expertise en al dan niet kostbare apparatuur zal centralisatie van bepaalde zorg (in academische ziekenhuizen) en lateralisatie van zorg (in één of enkele ziekenhuizen van het samenwerkingsverband) optreden. ${ }^{4}$ Ook zal meer in teamverband met andere zorgverleners worden gewerkt. Hele klinische afdelingen zijn zeer geschikt voor 'nurse-led care'. De opname- en ontslagprocedure, het management van het noodzakelijke klinische onderzoek en belangrijke aspecten van de follow-up kunnen heel goed door goed opgeleide verpleegkundigen worden gedaan, onder de verantwoordelijkheid van de specialist.

Meer zorg zal poliklinisch of zelfs thuis worden gegeven en het klinisch aandeel in de zorg zal verminderen. Daarnaast kan de toekomstige positie van de huisarts nog van grote invloed zijn op het inhoudelijk werk van de medisch specialisten.

Bij de zorg van de toekomst staat de patiënt centraal. Er zijn bedreigingen op het gebied van de continuïteit, die voor een deel kunnen worden opgelost door beter teamwork en geavanceerde technologie zoals het elektronisch patiëntendossier. Het moet mogelijk worden dat een behandelend arts op ieder gewenst moment via internet toegang krijgt tot de medische gegevens van de patiënt, zoals die op één of meerdere plaatsen in ons land zijn vastgelegd en opgeslagen.

Essentieel in het geneeskundig zorgproces blijft het consult tussen de patiënt en de arts, waarin op grond van de verkregen informatie en op grond van de mogelijke behandelingsvormen een besluit moet worden genomen over wat te doen. De centrale rollen van de patiënt ('patient centered care') en de arts ('the doctor in the lead') blijven overeind, maar veel van het noodzakelijke werk kan zinvol worden herverdeeld en overgedragen aan andere zorgverleners. 5

\section{De opleiding van de toekomst}

De hierboven geschetste ontwikkelingen hebben directe en belangrijke gevolgen voor de medisch specialistische opleidingen. Het CCMS heeft daarom de laatste jaren een aantal belangrijke initiatieven ontwikkeld (zie ook tabel 1).6-8 Naar analogie van het Raamplan Artsopleiding 1994 (en herzien in 2001) heeft het CCMS een werkgroep gevraagd algemene eindtermen voor de medisch specialistische opleidingen op te stellen. Bovendien is de wetenschappelijke verenigingen gevraagd om specifieke eindtermen vast te stellen voor de kennis en vaardigheden van de onderscheiden specialismen. Een goed voorbeeld is daarbij geweest het rapport van het Royal College of Physicians and Surgeons in Canada, het zogenaamde CanMEDS 2000 project. ${ }^{9}$ Als essentiële rollen van de medisch specialist in het nieuwe millennium worden daarin ge- 
Tabel 1. Initiatieven van het CCMS voor verbetering van de opleidingen (2001-2003).

- Algemene eindtermen voor alle specialismen gelijk;

- Specifieke eindtermen per specialisme volgens een zelfde format;

- Teach the teachers, inclusief feed-back geven;

- Curriculum met leerdoelen, bijvoorbeeld per half jaar (modules);

- Meer cursorisch onderwijs met actieve rol voor de AGIO;

- Skills labs;

- Meer zelfstandig leren;

- Meer tijd voor opleiding, minder kluswerk;

- Aangepast aantal diensten;

- Alle jaren van de opleiding parttime mogelijk;

- Persoonlijk portfolio;

- Jaarlijkse voortgangsexamens;

- Meer dagelijkse klinische momenten betrekken bij beoordeling;

- Andere zorgverleners betrekken bij de beoordeling van competenties;

- Jaarlijkse voortgangsgesprekken voor wederzijdse evaluatie van de voortgang van de opleiding op basis van het portfolio.

noemd: medisch expert, communicator, samenwerker, manager, gezondheidsadvocaat, docent die zelf ook bereid is om te leren en professional. Het CanMeds 2000 project en de algemene eindtermen van het Raamplan Artsopleiding 2001 zullen een belangrijke rol spelen bij het vaststellen van de algemene eindtermen die gaan gelden voor alle medisch specialistische opleidingen.

Het moge duidelijk zijn dat hier belangrijke stappen worden gezet. Niet alleen kennis en vaardigheden worden van belang geacht, maar ook de omgang met patiënt en familie, het werken in teamverband met andere zorgverleners, de bereidheid en vaardigheid om levenslang te leren, de vaardigheid om kennis en kunde over te brengen op anderen en vooral ook de positie van de specialist in de maatschappij, waarbij altijd zal worden opgekomen voor de individuele belangen van de patiënt, ongeacht tegenstrijdige maatschappelijke belangen. Het wordt voorzien dat deze algemene eindtermen in 2003 door het CCMS worden vastgesteld.
Voor wat betreft het opstellen van de specifieke eindtermen voor de kennis en vaardigheden van de onderscheiden specialismen zijn al belangrijke vorderingen gemaakt. Meer dan de helft van de wetenschappelijke verenigingen heeft dit belangrijke proces achter de rug. De rest volgt snel. Het is in het kader van de herbezinning over wat behoort tot het basisgedeelte van het specialisme en dus gekend en beheerst dient te worden door alle specialisten een nuttig proces gebleken. Binnen alle wetenschappelijke verenigingen is een discussie op gang gekomen over wat de basis van het vak is, wat een aandachtsgebied kan worden genoemd en wat zelfs een subspecialisme. Thans wordt de algemene gedachte ontwikkeld dat de opleiding onder toezicht van het CCMS tenminste gaat over de basis van het specialisme en een kennismaking met één of meerdere aandachtsgebieden. Bij het ontwikkelen van echte subspecialismen wordt meer gedacht aan een opleidingstraject na de gewone opleiding; een opleiding die dan niet onder het toezicht van CCMS en de Medisch Specia- 
listen Registratie Commissie valt, maar onder het toezicht van de wetenschappelijke verenigingen zelf.

Het CCMS voert thans een discussie over de mogelijkheid om meer tijd van de opleiding beschikbaar te maken voor de opleiding zelf, voor de ontwikkeling van modellen voor een effectiever gebruik van die opleidingstijd en voor de beoordeling van het resultaat van opleiden.

Het beschikbaar maken van meer tijd kan onder andere worden bereikt door 'oneigenlijk' werk niet langer door assistenten te laten verrichten maar door andere zorgverleners, een proces dat niet budgettair neutraal kan worden gerealiseerd. Ook wordt gedacht aan een vermindering van de werkzaamheden buiten kantooruren, zoals de diensten. Opnieuw een verandering die een beroep doet op andere menskracht. De beschikbare opleidingstijd kan beter worden benut door nieuwe onderwijsvormen te introduceren, die zijn gericht op het zelfstandig leren door assistenten en op het op interactieve wijze behandelen van bepaalde thema's op vaststaande dagen, bijvoorbeeld éénmaal in de twee tot vier weken. Het spreekt vanzelf dat daarbij ook gebruik zal worden gemaakt van internationaal beschikbaar onderwijsmateriaal en van skills labs. Het spreekt evenzo vanzelf dat de assistenten een leidende rol zullen krijgen in de presentatie en discussie van onderdelen van het thema en dat de leden van het opleidingsteam deze nieuwe onderwijsvormen moeten aanleren, inclusief het geven van feed-back. ${ }^{10}$

Tenslotte kan de effectiviteit van de opleiding ook worden verbeterd door een meer gestructureerde beoordeling van de assistent in opleiding en van de opleiding zelf. De algemene en specifieke eindtermen zullen worden opgenomen in een curriculum. Aldus zal een goede basis ontstaan voor de evaluatie van de verschillende opleidingsjaren door de opgeleiden en de leden van het opleidingsteam. Op deze manier wordt tijdig duidelijk welke aspecten van de opleiding voldoende aan bod zijn gekomen en welke aspecten extra aandacht behoeven. Een door alle assistenten zelf bijgehouden portfolio kan bijdragen aan een goede evaluatie van de opleiding en dus aan de verbetering van de kwaliteit ervan. Het proces van beoordelen van assistenten behoeft beslist meer aandacht en kan gemakkelijk in een continuüm worden geplaatst. Allerlei dagelijkse momenten lenen zich goed voor een beoordeling, voor het geven van directe feed-back en voor het aanbrengen van verbeteringen. Hierbij kan onder andere worden gedacht aan het ochtendrapport, het spreekuur, de patiëntenbespreking, de korte wetenschappelijke voordracht, de visite, het spreekuur en aan verrichtingen. Ook het oordeel van andere leden van het team, zoals verpleegkundigen en verloskundigen, kan een zinvolle aanvulling geven op de beoordeling van de assistent en in staat stellen tot tijdige correctie.

Het CCMS vindt het belangrijk dat alle opleidingsjaren parttime kunnen worden gevolgd, zodat ook zwangerschap en ouderschap tijdens de opleiding goed mogelijk zijn. Parttime opleiden betekent vooralsnog een verlenging van de totale duur van de opleiding. Dat is bij de huidige duur van de verschillende opleidingen een minder aantrekkelijk perspectief. Het CCMS heeft daarom allereerst gekozen voor een verbetering van de kwaliteit van de opleidingen door een aantal initiatieven zoals boven geschetst. Op den duur valt een echte verkorting van de opleidingen zonder een vermindering van kwaliteit te overwegen. Zelfs kan aan een meer individueel opleidingstraject, 
inclusief een variabele duur, worden gedacht.

Het CCMS heeft met belangstelling kennis genomen van het rapport 'De arts van straks' 11 en steunt de daarin genoemde initiatieven om een directe aansluiting te waarborgen tussen de opleiding tot arts en de vervolgopleidingen, en ook om een gedeelte van het laatste jaar van de artsopleiding, het zogenaamde schakeljaar, al te doen meetellen met de vervolgopleiding tot medisch specialist. ${ }^{12}$

De specialist van de toekomst staat borg voor kwaliteit, hij communiceert goed, geeft tijd en aandacht aan de patiënt, is in staat tot reflectie, voelt zich thuis in een team, is manager, schuwt het publieke debat niet, plaatst de patiënt centraal en blijft 'in the lead'. Het nieuwe opleiden verandert van onderwijs geven naar het helpen zelf te leren en het nieuwe beoordelen gaat niet alleen over kennis en vaardigheden, maar vooral over competenties. We gaan een mooie toekomst tegemoet.

\section{Literatuur}

1. Shine KI. Health care quality and how to achieve it. Acad Med 2002;77:91-9.

2. Bleker OP. Behandel de patiënt zoals uzelf wilt worden behandeld. Medisch Contact 2000;55(4):138-9.

3. Bleker OP, Blijham GH. Zorgen voor morgen. Medisch Contact 1999;54(11):384-5.
4. Bleker OP. Zorg verlenen in districten. Medisch Contact 2001;56:(43):1584-6.

5. Lilford RJ, Howie F, Scott I, et al. Medical practice: where next? J Roy Soc Med 2001;94:559-62.

6. Lange JJ de, Lagaaij MB, Hoog JC de. De medisch specialist van overmorgen. Medisch Contact 2001;56:300-2.

7. Centraal College Medische Specialismen. Centraal College Studiedag 1998: naar een nieuwe structuur voor de medisch specialistische opleidingen? KNMG: Utrecht; 1998.

8. Lange JJ de, Plasmans CMT, Hoog JC de, ed. 40 jaar Centraal College, opleiden in een veranderde maatschappij. KNMG: Utrecht; 2001.

9. Royal College of Physicians and Surgeons of Canada. Skills for the new millennium, report of the societal needs working group. Direction for specialists 2000 project; 1996. www.canmed 2000.

10. Peyton JWR, ed. Teaching and learning in medical practice. Silver Birches, Herts: Manticore Europe Ltd; 1998.

11. De arts van straks, een nieuw opleidingscontinuüm. Utrecht: KNMG, DMW-VSNU, VAZ, NVZ, LCVV; 2002

12. Ten Cate ThJ, Lagaaij MB, Blijham GH. Het zesde jaar als schakeljaar. Medisch Contact 2001;56: 455-8.

De auteur:

Prof. dr. O.P. Bleker is gynaecoloog, hoofd Afdeling Verloskunde \& Gynaecologie, Academisch Medisch Centrum, Universiteit van Amsterdam en voorzitter van het Centraal College Medische Specialismen.

Correspondentieadres:

Prof. dr. O.P. Bleker, Afdeling Verloskunde \& Gynaecologie H4-210, Academisch Medisch Centrum, Postbus 22700, 1100 DE Amsterdam, tel: 020-5663557, fax: 020-6971651,o.p.bleker@amc.uva.nl.

\section{Summary}

The medical specialist of the future is member of a team and works closely together with other healthcare professionals. He possesses the core knowledge and skills of his profession and has a special field of interest. To prepare residents for this future profile of their profession, general skills will become more important in medical education: competencies in medical knowledge and skills, communication, collaboration, management, learning and teaching and health care policy.

These changes will be made possible through teaching the teachers in medical education, learning and assessment procedures. 